\title{
Consumo entre gays: compreendendo a construção da identi- dade homossexual através do consumo
}

\section{Brazilian gays: understanding the construction of the homosexual identity through consumption}

\author{
Bill Pereira ${ }^{1}$ \\ Eduardo André Teixeira Ayrosa \\ Sayuri Ojima ${ }^{3}$
}

\section{Resumo}

Este estudo tem o objetivo de observar a subcultura gay e explorar as mudanças que ocorrem nos hábitos de consumo dos gays durante o rito de passagem da "saída do armário". Essa análise é crucial para se compreender a construção da identidade homossexual. Entrevistas em profundidade foram realizadas com 10 gays residentes no Rio de Janeiro entre outubro de 2004 e janeiro de 2005. Os resultados sugerem que:

- $\quad$ os gays interagem com produtos e marcas durante a construção da identidade homossexual; e

- $\quad$ os sujeitos utilizam os produtos numa estratégia de negação, camuflagem e reforço dessa identidade.

Palavras-Chave: consumo gay, identidade homossexual, identidade

\begin{abstract}
The focus of this study is the Brazilian gay (male homosexuals) subculture. Our objective is to explore the changes that occur in the way gays interact with the world of products during the process of "coming out of the closet". This analysis is important to understand the construction of the homosexual identity. Ten long in-depth interviews were carried out with gays residing in Rio de Janeiro between October 2004 and January 2005. The results suggest that products and services are actively used by gays in order to deny, camouflage, and reinforce their homosexual identity.
\end{abstract}

Key words: gay consumption, homosexual identity, identity

\section{Introdução}

A relação entre cultura e consumo tem interessado cada vez mais os estudiosos do comportamento do consumidor. Segundo McCraken (2003), cultura pode ser entendida como as idéias e atividades através das quais uma sociedade ou grupo fabrica e constrói os significados do mundo em vive. Estudar a forma como os indivíduos constroem esses significados através da compra e posse de bens tornou-se um ponto crucial para se compreender o comportamento do consumidor.

Ainda de acordo com McCraken (2003, p.11), grupos que vivem à margem da sociedade, como os gays, são "provedores de significado" e precursores de tendências para a cultura dominante. Essa criação de significados

\footnotetext{
${ }^{1}$ Doutorando de Administração pela Escola Brasileira de Administração Pública e de Empresas da Fundação Getulio Vargas - EBAPE/FGV. Endereço: EBAPE/FGV Praia de Botafogo, 190 - sala 528 - Botafogo - Rio de Janeiro/RJ - Brasil - CEP:22250-900. E-Mail: ebnunes@fgvmail.br.

2. Ph.D em Administração pela London Business School. Professor da Escola Brasileira de Administração Pública e de Empresas da Fundação Getulio Vargas EBAPE/FGV Endereço: Praia de Botafogo, 190 - sala 528 - Botafogo - Rio de Janeiro - RJ - CEP: 22250-900. E-Mail: ayrosa@fgv.br.

${ }^{3}$ Graduanda de Administração pela Escola Brasileira de Administração Pública e de Empresas da Fundação Getulio Vargas - EBAPE/FGV. Endereço: Praia de Botafogo, 190 - sala 528 - Botafogo - Rio de Janeiro/RJ - Brasil - CEP: 22250-900 - E-Mail: sayoc@fgvmail.br.

Artigo recebido em Janeiro de 2006 e aceito para publicação em abril de 2006.
} 
por parte da cultura gay também se reflete nos produtos, na música, nas artes e, em especial, na moda. Esses grupos têm sido alvo de vários estudos acadêmicos que procuraram investigar o mercado gay (BRANCHIK, 2002; FUGATE, 1993; HASLOP, HILL e SCHIMIDT, 1998; WALTERS e MOORE, 2002) e o consumidor gay (KATES, 2002, 2004; NUNAN, 2003). No entanto, a grande maioria desses estudos se restringiu aos EUA. Assim, esta pesquisa teve o objetivo de investigar o modo como homossexuais masculinos - doravante gays se relacionam com produtos e marcas. Baseados nos trabalhos de Kates (2002, 2004), assumimos que esse grupo pode ser observado e descrito como uma subcultura de consumo. Portanto, foram exploradas as mudanças ocorridas nos hábitos de consumo dos gays durante o rito de passagem da "saída do armário" - ou adoção pública da identidade gay -, um processo crucial na construção da identidade homossexual. Nesse sentido, Schoulten (1991) argumenta que em ritos de passagens os produtos e serviços são transformados em artefatos de consumos ritualísticos impregnados de grande valor simbólico. Belk (1988) sugere que as posses e o consumo ajudam a definir a identidade dos indivíduos.

O segmento de consumidores gays tem despertado a atenção do mercado no Brasil. Cada vez mais, a mídia vem se interessando por esse consumidor e tem focado sua programação para esse público. Esse interesse gera reportagens, cenas de novelas e chega a programas como o Fica Comigo gay, da MTV. Não só há programas específicos para homossexuais como também programações inteiras através dos canais pagos. A França lança seu canal de TV voltado para o público homossexual, a Pink TV, com a proposta de ser uma "emissora pluralista, que dê valor especial à cultura gay", cuja assinatura mensal custa 9 euros (LECUMBERRI, 2004). O Brasil também não fica atrás nessa idéia e lança seu primeiro canal nacional gay, o ForMan, canal da Globosat, que custará R \$30,00 mensais, transmitido pela Sky e pela Net. O concorrente do ForMan é o G Channel, oferecido pela DirecTV (CASTRO, 2005). Em 2005, a quinta rodada do Big Brother Brasil teve como vencedor de popularidade Jean Wyllys, um professor declaradamente homossexual.

Outro ponto que tem interessado os pesquisadores é a forma como os consumidores utilizam os produtos e marcas, e conseqüentemente os significados culturais atribuídos aos mesmos para a construção de várias identidades sociais, como as de gênero, raça ou mesmo profissionais. Entender como uma adolescente atribui significado a um produto (como um sutiã) na construção de sua identidade de mulher madura, ou como gays utilizam o simbolismo de produtos e marcas para a construção de uma identidade homossexual são alguns dos temas que têm norteado alguns estudos.

O campo do comportamento do consumidor tem se interessado especialmente em investigar como grupos de consumidores se relacionam com produtos e marcas para a construção de subculturas de consumo. Um dos trabalhos clássicos a esse respeito é o estudo de Schoulten e McAlexander (1995) com um grupo de motoqueiros americanos, os new bikers, que buscou investigar a forma como esse grupo se apropria da simbologia relacionada às motos Harley-Davison para a construção de uma subcultura de consumo. Esse grupo marcava sua diferença em relação à sociedade abrangente, não apenas por compartilhar uma mesma atividade e um estilo de vida próprio, mas também por adotar uma marca específica.

O termo subcultura pode ser entendido como os valores, símbolos e significados de um grupo restrito em oposição a uma cultura maior (MORGAN, 2000). Para alguns autores, o conceito de subcultura sugere que uma prática cultural estaria acima da outras e que todos os indivíduos subscreveriam essa cultura maior. Neste estudo, usaremos a definição adotada por Kates (1998) e Nunan (2003) que definem subcultura como uma ideologia articulada coerentemente num conjunto de significados, crenças e comportamentos; além de ser uma forma complexa de interação e organização social partilhada. 


\section{Referencial teórico}

\section{O Mercado gay e o consumidor gay}

Alguns estudos questionam a existência (PEÑALOZA, 1996; HASLOP, HILL e SCHIMIDT, 1998; KATES, 2002, 2004) ou não (FUGATE, 1993;) do mercado gay. Nos EUA, antes de 1941, já havia alguns produtos voltados para esse público. Por exemplo, algumas peças de vestuário já eram usadas como forma de reconhecimento e codificação entre os gays. Gravatas vermelhas e ternos verdes (BRANCHIK, 2002; KATES, 1998) eram produtos marcantes na comunidade gay americana até a década de 1940. Naquele período, os gays buscavam roupas com pouca demanda no mercado masculino (BRANCHIK, 2002).

O mercado gay - ou como denominado por Peñaloza (1996), the dream market -, muitas vezes observado como um fenômeno recente, na verdade, cresceu junto com o desenvolvimento da comunidade gay e do próprio movimento pelos seus direitos. O processo de urbanização que trouxe uma nova estrutura social está historicamente ligado ao crescimento do mercado gay, ao passo que, com o desenvolvimento das cidades, estas se tornaram o refúgio dos homossexuais em relação à vida no campo, que mantinha uma mentalidade extremamente conservadora quanto à sexualidade (ALDRICH, 2004; BRANCHIK, 2002). A vida nas cidades atraiu os gays não apenas pela maior liberdade, mas também por um fator que igualmente atraiu tantas outras pessoas: a oportunidade de melhorar de vida economicamente.

Em seu estudo sobre a história desse segmento de mercado nos EUA Branchik (2002) definiu essa fase inicial de acomodação do gay no contexto urbano como a fase underground (pré-1941). Nesse período, o mercado gay estava relacionado a atividades consideradas marginais, como casas de banho (termas), bares e bordéis; por isso, podemos considerar que os proprietários desses negócios foram os primeiros a se voltar para esse segmento.

Kates (2002) realizou um importante estudo sobre uma comunidade gay do Canadá. Para isso, imergiu em tempo integral num gueto gay urbano e passou a analisar como o grupo se valia do consumo para delimitar as barreiras dessa subcultura, os significados de consumo desse grupo e como os indivíduos utilizavam as práticas de consumo para se reconhecerem e se diferenciarem da cultura dominante. Esse estudo mostrou que a afiliação a essa subcultura estava associada a uma identidade social e, conseqüentemente, ao próprio consumo.

Na sua pesquisa, Fugate (1993) afirma que a não identificação de um mercado gay se deve ao fato de que, na época, havia "uma certa má vontade do mainstream business diante do mercado homossexual em ascensão". Isso decorria do temor de muitas marcas de terem sua imagem associada ao mercado gay, o que estaria relacionado ao receio da perda de clientes homofóbicos - com impacto significativo na receita da empresa - ou ao preconceito da própria organização contra o homossexual.

Peñaloza (1996) contrapõe o estudo de Fugate (1993) através de uma análise pós-moderna do segmento gay. Considerando os critérios tradicionais de segmentação rígidos demais para a avaliação desse mercado, o autor se baseia em estudos sobre movimentos sociais, cultura de consumo e teoria cultural pós-moderna. Ele reconhece uma forte interseção dos segmentos de mercado com os movimentos sociais, considerando que diversas questões do estudo de movimentos sociais, como identidade e subjetividade, também são críticas para o entendimento do lugar que gays ocupam no mercado econômico contemporâneo. A lógica está em pensar que membros de um movimento social como os gays tenham desenvolvido uma consciência de grupo como resultado de uma história comum entre eles; particularmente, pela sua exclusão, mobilização e luta em resposta ao estigma e aos preconceitos sofridos. Essa consciência é apenas parte da fundação do segmento de mercado. O estudo de Haslop, Hill e Schimidt (1998) parece confirmar isso, quando demonstra que a ida a locais gays, como bares, é uma importante aspecto do ritual de socialização da cultura gay e de construção da identidade homossexual. 
No Brasil o mercado gay também não é um fenômeno recente. Jornais como o Snob, na década de 1960, e Lampião, na década de 1970, as revista Sui Generis, nos anos 1990, e atualmente a G Magazine - com tiragem média de 90.000 exemplares por mês - são exemplos de publicações direcionadas para esse segmento (TREVISAN, 2000). As TVs a cabo como Net e DirecTV também investiram nesse segmento, não só criando programas específicos para gays, como também programações inteiras através dos canais pagos.

Apesar dessa aparente visibilidade, poucos estudos no Brasil tentaram traçar um perfil do consumidor homossexual. Um estudo realizado pela Silos Representações (1999) para a revista gay de maior circulação no Brasil identificou as seguintes características de seus leitores assumidamente gays: $48 \%$ têm nível superior, 39\% são das classes A e B, a renda mensal familiar é de em média $\mathrm{R} \$ 3.500,00$, gostam de freqüentar bares e boates direcionadas para o público gay e também gostam de gastar com viagens e roupas. Esses dados parecem condizentes com a visão politicamente correta do consumidor gay. Entretanto, pesquisas com rigor acadêmico no Brasil sobre esse consumidor enriqueceriam significativamente o conhecimento a respeito.

Em suma, o mercado gay se desenvolveu junto com a formação da comunidade gay, justamente, pela necessidade dos gays se identificarem. Muitas vezes, tal identificação se baseou no uso de certos produtos e marcas, que passaram a ser associados ao mundo gay. A formação da comunidade gay foi sendo reforçada pelos movimentos sociais relativos à causa homossexual.

\section{Identidade e autoconceito}

Para Hall (2004) o sujeito pós-moderno assume identidades diferentes em diferentes momentos, e essas identidades são dinâmicas e estão sendo continuamente deslocadas. Logo, segundo o autor, na medida em que sistemas de significação e representação cultural se multiplicam, somos confrontados com diferentes e possíveis identidades. No decorrer da vida, o homem pode construir (ou às vezes destruir) diferentes identidades, como a profissional, a de gênero ou a de pai de família.

Neste artigo, identidade é definida como um conjunto organizado de características de um indivíduo, representando o "eu" desse indivíduo em relação a uma situação social especifica (imaginária ou real). Assim, a identidade diz respeito à inserção do indivíduo numa categoria social (como raça ou orientação sexual). Quando deslocada dessa situação social que a ativa, essa identidade pode tornar-se latente (NUNAN, 2003; TROIDEN, 1984; CASS, 1984).

Outro ponto importante é compreender a diferença entre identidade e autoconceito. Cass (1984, p.110) define autoconceito como a "totalidade dos pensamentos e sentimentos que um indivíduo tem em relação a si próprio”. Seria então a auto-imagem que o indivíduo tem de si próprio. Segundo Sirgy (1982), o autoconceito se refere à maneira como as pessoas percebem a si próprias e está dividido em idealizado (como a pessoa gostaria de ser percebida) e real (como a pessoa apresenta o seu eu para os outros).

Nessa discussão, assumiremos autoconceito como a imagem formada pelo que o indivíduo pensa a respeito de si como objeto social. Essa percepção do eu informa ao indivíduo uma imagem de si como um certo tipo de pessoa, possuidora de hábitos, posses, relacionamentos, determinados aspectos físicos e formas de comportamento, e resulta da evolução da história, das experiências e interações vivenciadas pelo indivíduo.

Apesar do autoconceito ser definido num nível individual, podemos estendê-lo a um nível coletivo, porque em algumas culturas, lugares e tempos na história do mundo a noção do "self" é mais coletiva que individual (BELK, 1988).

É interessante notar como o autoconceito pode ser útil nos estudos sobre comportamento do consumidor. Um dos exemplos que ilustra a utilização desse conceito é o trabalho de Miranda, Garcia e Leão (2001) que qualifica o autoconceito como a melhor variável, em detrimento de classe e idade, para explicar as preferências pelo consumo de produtos da moda. Nesse estudo, os autores partem do pressuposto de que o conteúdo simbólico do 
produto só é apropriado quando reforça a maneira pela qual o consumidor pensa a respeito de si, chegando até mesmo a afirmar que "a dinâmica do processo de consumo está em se identificar".

Logo, identidade e autoconceito diferem entre si, pois a identidade se refere a uma situação social específica enquanto o autoconceito, não. A identidade está relacionada a uma categoria social que representa o seu eu numa situação social. Uma pessoa tem um autoconceito e muitas identidades. $\mathrm{O}$ indivíduo tem a necessidade de agir de acordo com o seu autoconceito e "ativará" uma determinada identidade conforme uma situação social específica (MASCETTI e PEREIRA, 2004).

Como a identidade é pontual, a escolha do aspecto da identidade a ser expresso - seja ele ideal ou real, individual ou social - é motivada e influenciada pela situação com a qual o indivíduo se depara. Assim, o processo de aquisição de identidade vai ocorrendo - de forma complexa e de acordo com as situações vivenciadas pelos indivíduos -, comportando "relações positivas de inclusão e relações negativas de exclusão." (BADINTER apud NUNAN, 2003). Esse processo de construção da identidade é complexo e muitas vezes doloroso. Neste estudo, será vital entendermos como se dá a construção da identidade homossexual masculina.

\section{Construção da identidade homossexual}

Como visto anteriormente, a identidade é um rótulo com o qual as pessoas se classificam e que representa o self numa situação social (TROIDEN, 1984; NUNAN, 2003). Um indivíduo que se classifica na categoria de homossexual ativa essa identidade homossexual numa situação social específica (como uma parada gay) e a deixa dormente em outras situações (como no ambiente de trabalho). Dessa forma, a identidade homossexual é apenas uma das várias identidades que compõem o autoconceito do indivíduo. Assim, a identidade homossexual se refere à percepção que o indivíduo tem de si como homossexual em relação a uma situação social (CASS, 1984; TROIDEN, 1984).

Antes de analisar o processo de construção da identidade homossexual, é necessário levantar alguns pontos. O estigma que envolve a homossexualidade afeta tanto a formação quanto a expressão da identidade homossexual; e a formação da identidade homossexual envolve uma gradual aceitação do "rótulo" homossexual para si.

Várias teorias sobre formação da identidade têm sido elaboradas nas últimas décadas, muitas delas propondo um modelo de "estágios" pelos quais o sujeito passaria ao longo da construção da identidade homossexual (CASS, 1984; ELIASON, 1996; TROIDEN, 1984). Um dos modelos mais influentes na literatura de psicologia, proposto por Cass (1984), afirma que a formação da identidade homossexual segue cinco estágios: confusão, comparação, tolerância, aceitação, orgulho e síntese.

Neste artigo, adotaremos o modelo elaborado por Troiden (1989), e adotado por Nunan (2003), que afirma que a construção da identidade homossexual envolve quatro estágios típicos:

- sensibilização - ocorre normalmente antes da puberdade, quando o indivíduo começa a se sentir marginalizado e diferente dos demais;

- confusão - ocorre quando a possibilidade de uma possível homossexualidade pode provocar conflitos internos nos indivíduos. Nessa fase, o indivíduo tem um status sexual ambíguo. A ignorância e o estigma que envolve a homossexualidade é uma das causas desse estado de confusão. É quando os indivíduos recorrem a estratégias de fuga, camuflagem e de aceitação (parcial) da sexualidade;

- $\quad$ suposta identidade - quando a homossexualidade é aceita como identidade e é revelada apenas a outros homossexuais. Definir a si como homossexual e se apresentar para outros homossexuais como tal é um dos primeiros estágios do processo de saída do armário. Nessa fase, ocorrem importantes acontecimentos para o indivíduo, como o primeiro contato com grupos e locais gays; 
- compromisso - estágio final, nessa fase a homossexualidade é vista como um modo de vida. Nesse estágio, a identidade homossexual é percebida de forma confortável e plena.

À medida que o indivíduo passa de um estágio para o outro, seu autoconceito passa de mais negativo para mais positivo e aumenta seu bem-estar. Ele passa a aceitar sua identidade homossexual, adotando comportamentos condizentes com essa nova identidade (KATES, 1998; NUNAN, 2003; TROIDEN, 1989). Vale ressaltar que esses estágios não são lineares, nem que todos os indivíduos passem por eles da mesma forma. Trata-se apenas de um modelo que apresenta uma enorme variação em termos da idade cronológica dos indivíduos ao levarem a cabo esse processo.

\section{A saída do armário: um rito de passagem}

A saída do armário (coming out of the closet) pode ser considerada um importante rito de passagem vivido pelos indivíduos durante o processo de construção de uma identidade homossexual. É um processo crítico na vida do gay, durante o qual se aprende sobre os valores e comportamentos da cultura gay e se assume uma identidade homossexual para si e para os outros (CASS, 1984; KATES, 1998; NUNAN, 2003; TURNER, 1974; TROIDEN, 1989). Segundo Trevisan (2000), o sujeito faz a opção de ser socialmente homossexual, não apenas de desejar homossexualmente. A própria identidade do indivíduo só é completamente construída após a aceitação no grupo. Enquanto a homossexualidade não é considerada uma escolha (CASS, 1984; TROIDEN, 1989), pode-se dizer num sentido mais amplo que o indivíduo realmente escolhe adotar uma identidade homossexual quando atravessa o rito de passagem da saída do armário (KATES, 1998; NUNAN, 2003).

Segundo Carmo (2001), o termo "rito de passagem" - definido pelo antropólogo Van Gennep (1969, apud TURNER, 1974) - estaria relacionado com os momentos pelos quais o indivíduo passaria ao transitar (ou deslocar-se) de uma situação, ou posição social determinada (estruturada), para outra posição ou situação que ele ainda desconheça. Ao longo dessa transição, o indivíduo permanece mergulhado no estado de communitas (momento em que ele se encontra fora de uma situação controlável, fora de uma posição socialmente demarcada, estruturada). O indivíduo permanece nesse estado de communitas enquanto não assimila sua nova condição; ou seja, enquanto não assume identidade, condutas e papéis inerentes à sua nova posição social. O rito de passagem, portanto, é caracterizado por três fases distintas:

- $\quad$ separação - afastamento do ponto fixo anterior na estrutura ou condição social;

- margem ou liminaridade - momento caracterizado por uma ambigüidade, em que o indivíduo permanece num domínio cultural com poucos atributos do passado e do futuro, num estado comparado à morte, devido à ausência de identidade ou referenciais quanto à posição social; e

- reagregação - reinstalação do indivíduo numa posição diferente da que ocupava antes do ritual e mais elevada socialmente, em que lhe são conferidos atributos pertencentes a uma nova posição num determinado sistema.

Essas fases do rito de passagem definido pelo antropólogo Van Gennep (1969, apud TURNER, 1974) podem ser análogas a algumas dimensões do modelo proposto por Troiden (1989), citadas anteriormente. Para este estudo, será feita a seguinte analogia:

- $\quad$ sensibilização - quando o indivíduo começa a se sentir marginalizado e diferente dos demais. Seria análoga à separação;

- a confusão - quando uma possível homossexualidade pode provocar conflitos internos no indivíduo. Seria análoga à liminaridade. Nessa fase, o indivíduo vive num estágio liminar onde ele está deixando para trás os padrões heterossexuais de comportamento e assimilando novos padrões, ligados à cultura gay. Nesse estágio, sofre as conseqüências dessa ambigüidade, dessa ausência de identidade determinada; 
- suposta identidade e o compromisso - fase em que o indivíduo, antes de tudo, revela-se como homossexual apenas para os seus pares e, finalmente, quando a homossexualidade é aceita por ele próprio e, de certa forma, legitimada socialmente. Nesse estágio, a identidade homossexual está relacionada a um modo de vida. Esse ponto seria análogo à reagregação.

Dessa forma, consideraremos neste estudo que o rito de passagem da saída do armário é composto de três fases. Além disso, é importante ressaltar que esse processo de saída do armário reflete o desenvolvimento psicológico de uma identidade social (nesse caso, a identidade homossexual); uma crescente aceitação da identidade homossexual como parte do autoconceito do indivíduo e, finalmente, um processo progressivo de revelação de um status social estigmatizado (gay) para vários públicos: amigos, família, outros gays e heteros. Segundo alguns autores, esse processo está intimamente relacionado com a mudança nos padrões de consumo do indivíduo (KATES, 2002; NUNAN, 2003; TREVISAN, 2000; TROIDEN, 1989).

Kates $(1989,2002)$ demonstra no seu estudo que o consumo apresenta variações entre esses estágios; ou seja, os produtos consumidos e as experiências vividas nessa fase têm um papel importante na criação e manutenção de uma identidade homossexual.

\section{Metodologia}

Como um estudo exploratório-descritivo do comportamento do consumidor, este artigo procurou empregar uma metodologia que permitisse a emergência de categorias êmicas (emic categories, vindas do campo do próprio entrevistado), descrevê-las, cruzá-las entre si e, por fim, contrastá-las com o referencial teórico disponível na área. Este estudo, portanto, tem um caráter interpretativo.

A principal técnica de coleta de dados primários utilizada foram entrevistas em profundidade, a partir de um roteiro semi-estruturado (McCRAKEN, 1988) com 10 homossexuais masculinos do Rio de Janeiro. Para ser entrevistado, o indivíduo deveria ser assumidamente homossexual. Para selecionarmos os sujeitos da pesquisa foi empregada a técnica snowball sampling (ou amostragem por "bola de neve"), na qual um sujeito entrevistado convida um dos seus amigos para participar, o qual por sua vez convida outro amigo e assim por diante. Essa técnica foi utilizada por Kates (1998) e Troiden (1989) em seus estudos de grupos homossexuais. Uma caracterização dos entrevistados pode ser vista na tabela 1.

Tabela 1

Perfil dos entrevistados

\begin{tabular}{ccc}
\hline Entrevistado & Ocupação & Idade \\
\hline 1 & Advogado & 32 \\
\hline 2 & Analista financeiro & 28 \\
\hline 3 & Assistente comercial & 30 \\
\hline 4 & Designer & 42 \\
\hline 5 & Estudante de odontologia & 22 \\
\hline 6 & Publicitário & 36 \\
\hline 7 & Estudante de administração & 25 \\
\hline 8 & Diretor de segurança & 38 \\
\hline 9 & Engenheiro & 38 \\
\hline 10 & Administrador & 24 \\
\hline
\end{tabular}

As entrevistas foram gravadas por processo digital; e depois, transcritas. O trabalho sobre as transcrições e gravações foi o de identificar categorias importantes para a compreensão das estruturas subjacentes ao discurso. Esse processo levava os autores não apenas a insights sobre os discursos, mas também à releitura e aprofundamento da teoria no campo. A cada entrevista, era realizada uma nova categorização e uma nova volta à literatu- 
ra, num processo circular. Dessa forma, uma entrevista alimentava a outra, que gerava novos insights, que alimentavam as entrevistas por vir. Interrompemos o processo no momento em que as entrevistas não forneciam mais informações novas.

Mesmo que toda metodologia de pesquisa tenha limitações, os insights que ela gera ajudam a anular suas imperfeições instrumentais. Ainda assim, cabe elencar aqui as possíveis falhas metodológicas enfrentadas neste estudo.

O método de pesquisa escolhido exige que o pesquisador tenha uma significativa habilidade interpretativa para abordar o conteúdo observado. De fato, o pesquisador não chega a campo ingenuamente, despido de teorias. Logo, seu olhar é direcionado para aquilo que considera relevante, o que pode desviá-lo de algo que seja importante para o entendimento do seu objeto de estudo. Além disso, em algumas entrevistas ficou claro que quando o informante está muito cônscio de si mesmo, tende a racionalizar suas respostas e, portanto, a mascarar o objeto de análise da pesquisa.

\section{Análise das entrevistas}

A avaliação dos dados foi feita pela análise do discurso dos informantes. As categorias apresentadas emergiram espontaneamente nas entrevistas feitas durante a pesquisa. Exploramos como os sujeitos utilizaram os vários significados culturais do mundo dos produtos quando da descoberta e aceitação da homossexualidade. Adiante, apresentaremos as categorias mais marcantes identificadas, organizadas de acordo com a fase do processo de saída do armário.

\section{A descoberta}

A primeira fase no processo de saída do armário é o que chamamos de "descoberta". É o momento na vida do indivíduo que começa com uma sensação de desconforto e termina com a tomada de consciência da sua condição homossexual. Quatro categorias surgiram nessa fase: conflito, negação, busca de informações e ambivalência.

\section{Conflito}

O primeiro ponto que aparece de forma recorrente nos discursos são os conflitos internos gerados pela descoberta da possibilidade da homossexualidade. Esse momento leva a relatos muito semelhantes, e todos usam termos ou expressões que remetem a conflito para caracterizá-lo: "Eu achava que não era uma coisa natural, entendeu?"

Uma das formas usadas para negociar internamente com o conflito gerado pela sensação de deslocamento foi generalizar a condição homossexual para o resto do mundo. Um dos entrevistados chegou a afirmar que "no fundo, todo mundo é sempre gay". Essa tendência à generalização dará lugar, no futuro, a uma profunda consciência da diferença entre os grupos homossexual e heterossexual. No entanto, o que impera nessa fase é a sensação de deslocamento, muitas vezes, não identificado. Antes mesmo dos sujeitos cogitarem da homossexualidade, eles já se percebiam excluídos, diferentes e pressionados a dominar e controlar seus impulsos. Em um dos relatos, por exemplo, o entrevistado disse que fora "obrigado" a ser calmo:

Eu nunca tive muito interesse por garotas. Eu era mais calminho; mais calminho não, eu era obrigado a ser calmo [...] porque quanto mais eu expandisse, mais eu colocaria a minha posição na família em xеque. Então, eu sempre me senti obrigado a ser calmo, a ficar na minha, a falar baixo.

Não encontramos nenhuma menção a produtos ou serviços diretamente relacionados com essa fase; talvez, porque ela esteja geralmente associada à infância. Na verdade, podemos supor que as relações das crianças com o mundo dos produtos podem, no futuro, vir a ser fonte de conflitos. 


\section{Negação}

O conflito entre um discurso que trata os gêneros de forma binária (masculino/feminino) e a condição homossexual, referenciada nesse discurso como desviante (KATES, 1998, 2002), faz com que os indivíduos se deparem com o estereótipo negativo do gay. Segundo esse estereótipo, "ser gay" estaria relacionado ao comportamento feminino ou ao uso de produtos relacionados com o mundo feminino. Veja o seguinte relato:

Eu ouvia que para você ser veado, você tem que ter jeitinhos transloucados, você tem que colocar uma roupinha, você tem que ter uma espécie de estereótipo preestabelecido, e isso me chocava.

Como uma reação a essa visão, os sujeitos usam produtos - em especial, a moda como um instrumento de teatralização (MIRANDA, GARCIA e LEÃO, 2001) - para negar essa possível homossexualidade e reforçar a masculinidade. Afinal, a exposição do comportamento desviante pode gerar punição (GOODE, 1990). É interessante notar nos relatos que os entrevistados apresentam um autoconceito negativo de si mesmos, e freqüentemente usam palavras que signifiquem punição ou prisão como "travado", "preso" e "sufocado".

“Antigamente, eu me via muito preso; não fazia as coisas com medo.”

“Eu acho que naquela época eu era muito travado.”

É interessante notar que uma das formas de punição pode vir do próprio indivíduo; ou seja, há um comportamento autopunitivo. Veja o seguinte trecho:

Eu não me aceitava. Naquela época, eu acho que eu era bem cafoninha, bem cafoninha. Enquanto eu não assumi de fato ser gay, era bem cafoninha. Assim, comprava umas roupas, assim, na loja mais careta possível; sabe calça de prega?

O entrevistado usou o termo "cafoninha" três vezes nesse momento. É interessante notar um termo êmico que emergiu nas entrevistas: todos os entrevistados referem-se aos heterossexuais como "caretas", e os termos "careta" e "cafona", apesar de não serem sinônimos, são bastante compatíveis. O produto mencionado, calça de pregas, é tipicamente relacionado ao mundo heterossexual, tido como um forte significante de heterossexualidade; ou seja, a punição consiste em travestir-se do seu gênero algoz.

\section{Busca de informações}

A suspeita de homossexualidade e o risco de ser categorizado de acordo com o estereótipo do gay levam os informantes a buscarem informações sobre temas ligados à homossexualidade. Vários produtos como livros, revistas, filmes e sites na Internet são consumidos com o objetivo de se compreender e superar os conflitos desse momento. Essa busca por informação é uma forma de derrubar o estereótipo negativo relatado anteriormente.

Eu sempre procurei entender o que é que estava acontecendo, por que eu era gay. Aí, eu procurava em enciclopédias; aí, tinha uns fascículos nas bancas de vida sexual, que eu comprava e colecionava, sabe? Procurava ler, lia demais. Tudo que tinha a palavra homossexualidade eu estava lendo para saber o que é que era. Porque aí eu fui entender que não é só o fato de transar com outro cara, é uma gama enorme de comportamento e gosto e preferência e coisas que não têm a ver com um arquétipo que as pessoas de uma certa forma acreditam.

Portanto, produtos não apenas compõem o imaginário desse grupo, mas ajudam na construção de identidade. Em alguns casos, produtos são transmissores diretos e literais dos ideais do grupo. Revistas e jornais são fundamentalmente utilitários, informativos, e muitas vezes de valor simbólico muito baixo (senão negativo, como no caso de jornais gratuitos).

\section{Assimilação}


Esse momento é marcado pela identificação com o grupo e a construção de uma identidade homossexual ainda restrita ao grupo gay, e apenas a ele revelada. Importantes momentos norteiam os relatos dos entrevistados ao longo desse estágio: os primeiros contatos com a cultura gay, a assimilação de padrões gay, as estratégias de reforço e camuflagem da identidade gay e a valorização estética.

\section{Entre dois mundos}

Esse foi um dos aspectos mais reveladores da pesquisa. Os indivíduos descreveram reiteradamente o momento em que viviam entre dois mundos. Dessa forma, eram influenciados, de um lado, pelos os padrões do mundo heterossexual de onde vinham, e de outro, pelos do mundo homossexual com o qual estavam tendo os primeiros contatos.

Segundo Turner (1974), os indivíduos entram num "estado de limiaridade" devido à ausência de identidade ou de referenciais quanto à posição social. Sentimentos como medo de ser descoberto, curiosidade e ambigüidade dominam os relatos nesse ponto.

No começo, você morre de medo de tudo. Tu não quer que ninguém saiba, tu não quer que te vejam com um homem na rua. Você está fazendo um negócio e está errado; então tu acha que está todo mundo vendo.

Eu tinha amigos que não sabiam, e eu também não queria abrir. Em determinados momentos, eu fazia uma vida gay sozinho. Eu ia às vezes a uma festa gay; às vezes eu não tinha coragem de entrar, ficava na porta, ficava rondando para ver como era, e tal.

Essa sensação de ambivalência e limiaridade estende-se às relações sociais de tal forma que as relações com grupos de amigos passam por um claro período de redefinição. Como os grupos de amigos mudam, é natural que os hábitos de consumo de mercadorias e serviços também mude. Veja este trecho:

[...] Então, eu saía com meus amigos heteros, e, depois, já de madrugada, ao invés de eu ir para a casa, eu ia para a porta da Le Boy; e aí, depois de um tempo, eu comecei a ir, e eu meio que achei meus novos amigos.

Nesse momento é possível, de fato, identificar as primeiras referências claras ao uso de produtos como identificadores da condição homossexual, mas ainda mesclados com relatos de tentativas de disfarce. Tanto as estratégias de identificação quando de diferenciação em relação ao mundo gay são completamente baseadas numa sintaxe atribuída pelos membros do próprio grupo aos produtos: são preferidas as roupas que revelem o corpo, o corte mais informal, tênis, jeans. A roupa que identificada com o mundo heterossexual é parecida com a roupa de trabalho.

Usava camisa social pra sair, com sapato, roupa. Hoje em dia, eu saio de camiseta, de calça jeans e tênis, que assim, claro, depende do lugar que você vai. Pra lugar hetero eu não vou assim tão largado.

\section{Primeiros contatos}

Segundo Haslop, Hill e Schimidt (1998), os ambientes gays como bares, boates ou um ou outro ponto gay na praia são locais próprios de expressão da subcultura gay. Nesta passagem, o informante diz que encontrou o seu mundo:

Um dia, um amigo gay me chamou para sair. Ele falou:

- Eu vou te levar num lugar.

- Que lugar que tu vai me levar?

- Praia, Ipanema, Farme de Amoedo! 


\section{Eu [risos] me encontrei. É meu mundo!}

Essa expressão também ocorre através do consumo. Como veremos, adiante, em outra categoria, várias marcas foram mencionadas pelos entrevistados como fortes símbolos dos gays. Contudo, nesse momento, o tipo de consumo que parece mais presente é o consumo do espaço dirigido a esse grupo; ou seja, o consumo de um serviço.

A primeira vez que fui a uma festa gay, eu senti que eu estava livre, entendeu? Eu me sentia no meu ambiente, não como na rua, que você não pode abraçar, não pode beijar, entendeu? Hoje em dia, praticamente, só freqüento locais gay, $90 \%$ são locais gays.

Um dos momentos mais relevantes observados nos discursos são os primeiros contatos com ambientes gays. Segundo Troiden (1989), esses primeiros contatos com bares e boates gays são determinantes para a assimilação cultural e a construção da identidade homossexual. O sentimento de identificação e liberdade ao ir a um ambiente gay está presente na maioria dos discursos. Isso pode ser claramente percebido no relato de um dos entrevistados, que disse sentir "felicidade, eu acho que eu senti naquela época era essa coisa de independência, assim, tenho um espaço". Após o impacto do primeiro momento, os relatos demonstram sentimentos de bemestar e conforto.

\section{Imitação}

Com o encontro com a cultura gay, os sujeitos entram num estágio de assimilação dos padrões dessa cultura. Esse processo de assimilação cultural é descrito por Van Gennep (1969, apud TURNER, 1974) como um período transitório pelo qual passa o indivíduo, para finalmente, incorporar um novo status. De acordo com Kates (2002), as primeiras idas a ambientes gays são um importante rito de passagem para que o gay adquira um novo status depois de um período de separação e liminaridade. Nesse período, a construção da identidade homossexual efetivamente se inicia.

A presença de marcas aqui é fundamental. As marcas fornecem o código necessário para a identificação dos integrantes do grupo. Veja no trecho a seguir a presença de marcas e locais de lazer.

Se você vive no mundo gay, você acaba focando geralmente em marcas que as pessoas usam, aquela aceitação. Então, você acaba procurando marcas caras; e você acaba dando o seu jeito pra você meio se inserir no grupo, porque todas as pessoas procuram estar num parâmetro de consumo igual, ou freqüentam o mesmo lugar; o lugar tal é melhor, é o mais badalado; eu vou dar um jeito de ir, ou a roupa tal é a que as pessoas estão usando, ou vou comprar.

Não apenas a marca é importante, mas também o preço dessa marca. Na verdade, o preço alto dessas marcas é mencionado em vários relatos. Em uma ocasião, o entrevistado disse que nunca seria capaz de pagar mais de $\mathrm{R} \$ 800$ por um jeans da Diesel. O mesmo entrevistado mencionou o nome Diesel mais 16 vezes no espaço de 80min da entrevista. O fascínio pelas grifes é enorme. A simbologia dos produtos e marcas é o assunto do próximo tópico.

\section{Simbologia dos produtos}

Um intenso processo de assimilação dos padrões culturais, principalmente estéticos, começa na vida dos entrevistados no início da sua socialização com o grupo gay. Nesse momento, os produtos que têm seu significado simbólico associado a gays são considerados produtos que "saíram do armário" (KATES, 2002) e se tornam referências positivas. Produtos e serviços que encontram esse caminho cativam esse público. Veja a descrição da experiência num hotel:

Eu gosto de viajar e ficar em hotel gay. [...] eu gosto da sensação de poder tomar o café da manhã junto com o meu namorado; assim, se quiser dar um beijo, se quiser tocar na mão, são coisas que a gente se acostuma a não fazer pra não chocar ninguém. 
Notamos nesse momento a importância quase exagerada que é dada a marcas como, por exemplo, Osklen, Triton, Forum, Diesel, Puma, Foche, ou Yes Brasil. Observamos também que exageros podem acontecer: alguns entrevistados dizem comprar roupas para parecer gays. Mais freqüente é a menção à forma de vestir alinhada com o grupo gay. Veja o seguinte relato:

Lugar gay é mais fashion, uma camisa mais regata, mais colorido, um tênis mais fashion também, uma calça jeans um pouco mais justa.

Portanto, não apenas as categorias de produto, as marcas ou os lugares são associados ao grupo gay. O modo de usar esses elementos também ganha uma gramática própria, e que deve ser conhecida não apenas por membros do grupo, mas também por empresas que desejam atingir o grupo. Quanto à relação entre qualidade e preço, ela vai além dos limites que normalmente lhe são reconhecidos. O preço compra a fuga do convencional, e isso dá prazer. $\mathrm{O}$ anticonvencionalismo custa caro.

Dificilmente você vai ver um gay de blusa para dentro, sapato combinando com o cinto, entendeu? Vai ver ele com tênis bem da moda, um tênis Nike, Puma, um tênis caro. Às vezes, não é nem muito pela beleza da peça, é pelo preço também. Um tênis que custa caro, aquilo já faz com que se tenha prazer de usar. Se você tiver um tênis de $R \$ 100,00$ e um de $R \$ 500,00$, é muito mais prazeroso usar o de quinhentos. Uma calça jeans, uma calça mais desbotada, uma calça com algum detalhe, com bolsos grandes, fugindo do convencional, e camiseta justa, camiseta de malha, geralmente, mais justa, que modela o corpo, mais colorida, vermelha, amarela, azul-claro, entendeu?

\section{Culto ao corpo e moda:}

Os sujeitos entrevistados mencionaram, enfaticamente, um padrão estético relacionado à cultura gay. Esse padrão enfatiza o culto ao corpo e a valorização das marcas e da forma de vestir. Fica evidente nos discursos a influência dos padrões da cultura gay na mudança dos hábitos de consumo dos entrevistados. Muitos relatam que começaram a procurar academias de ginástica, utilizar cosméticos e a comprar certos tipos de roupas depois que passaram a freqüentar o mundo gay.

[...] você vê em boate gay, o pessoal é mais forte. Você acha legal; é, "pô, eu tenho que ficar assim". Aí, estou malhando com mais freqüência por causa disso também.

Acho que até roupas de marcas, roupas caras são símbolos gays, porque o gay geralmente tem a necessidade de comprar roupas caras, de marca e tal. Eu acho que o culto ao corpo exacerbado é um símbolo gay. Não estou dizendo que os heterossexuais não tenham esse comportamento, mas que são típicos de gay, são.

Há uma clara interação entre a estética das roupas e a do corpo, como se um fosse uma extensão do outro. Há preocupação em escolher roupas que revelem o corpo de quem veste. E isso se sobrepõe à percepção da qualidade das roupas. É freqüente a menção ao fato de o público gay ser particularmente exigente, não apenas nos produtos tangíveis, mas também no trato com serviços. Isso tudo faz parte do traço "vaidade" - e da valoração positiva desse traço -, presente em todas as entrevistas.

Roupas para gays são transadas, mais justas, que modelam o corpo. Aí, entra a parte do culto ao corpo, a vaidade de manter o corpo em forma para poder mostrar, para você aparecer atraente [...] porque o gay gosta de marcas boas, gosta de andar bem vestido, é muito vaidoso...

\section{Aceitação}

Alguns entrevistados relataram que estão num estágio da vida onde a identidade gay já está plenamente aceita e transmitem sentimentos de tranquiilidade e bem-estar com a vida. A análise do discurso parece sugerir que apesar dos padrões estéticos gays ainda serem seguidos, e talvez manterem a mesma força simbólica, não são seguidos com tanta determinação. Afinal, já estamos falando aqui de um indivíduo com uma identidade definida, 
e em cuja identidade está impresso o seu gênero: homossexual masculino. Naturalmente, ter um grupo de amigos gays é de vital importância, pois todos são da comunidade. Mas o fato de pertencer a essa comunidade já não é mais incompatível com a presença como gay em outras comunidades não-gays. Essa tranqüilidade, endossada por uma identidade estável (por exemplo: "acho que consegui atingir uma tranqüilidade hoje na minha vida, pelo fato de ser gay, uma maturidade") tem efeitos sobre os padrões de consumo. Veja este relato:

[...]comecei a me sentir mais seguro para trazer os trabalhos, procurar empregos melhores e barganhar salários melhores e tudo mais; e, aí, também com isso eu acabei tendo menos entrave, acabei consumindo mais coisas que eu estava a fim.

Essa estabilidade e tranquiilidade parecem levar os indivíduos a se relacionarem menos ansiosamente com o mundo dos produtos. Como o reforço constante da identidade gay não é mais uma prioridade, nem tampouco o esforço de mimetização com heterossexuais $\square$ o ambiente de trabalho, por exemplo, o consumo simbólico de marcas perde um pouco de sentido. Entrevistados nesse estágio chegam a ter uma atitude asceta em relação a locais e produtos gays, e em alguns momentos até de rejeição.

\section{Invisibilidade}

Os entrevistados reconhecem que tanto o mundo gay como o modo de vida gay é visto como uma realidade invisível para a cultura dominante. Contudo, os entrevistados adotam esse modo de vida e o vêem como precursor de tendências. Esse ponto parece condizente com o que diz McCraken (2003), no sentido de que os grupos responsáveis por uma reforma radical do significado simbólico dos produtos são aqueles que vivem à margem da sociedade. $O$ relato que segue é bastante revelador nesse sentido:

[...] ser gay é você estar na periferia, mas como um complemento para a sociedade. Eu acho que o gay é como o mangue no ecossistema, ele está ali por fora, mas ele serve ao canal de reciclagem.

Ao longo de todas as entrevistas, repetiu-se o fato de gays com identidade madura serem capazes de identificar outros gays, mas não serem identificados pelos heterossexuais. Isso parece oferecer a eles não apenas a proteção de um código que só é percebido pelos insiders no grupo, mas também o orgulho de ter um código próprio. Devemos reconhecer que, com base nas entrevistas, esse código está em grande parte nos significados atribuídos aos bens e serviços.

\section{Conclusão}

Este artigo teve como objetivo investigar, de uma perspectiva interpretativa, homossexuais residentes no Rio de Janeiro. Empresas têm visto os homossexuais como um objetivo rentável de marketing, mas não revelam - ou não conhecem - informações mais ricas sobre o seu modo de vida que apenas uma abordagem interpretativa de pesquisa pode fornecer. O estereótipo do gay de classe alta com conta bancária recheada pode até ser verdadeiro, mas descreve o grupo de forma extremamente simplista, pobre até. O conhecimento sobre o modo como a comunidade se aproxima de produtos, usa-os, atribui a eles significados e os descarta é bastante mais ilustrativo e útil para o executivo interessado em investir nesse segmento. Nesse sentido, este estudo foi uma tentativa de desvelar algumas dessas estruturas.

Primeiro de tudo, reforçamos uma conclusão já constatada nos trabalhos de Kates (1998, 2002, 2004): a de que o mundo dos bens e serviços de fato oferece ao grupo um código extremamente rico de identificação dos seus membros. Esse código é usado para auxiliar a construção da identidade homossexual dos membros do grupo, para facilitar o acesso desses membros a serviços, para reduzir riscos (principalmente psicossociais) relacionados com essa identidade e para diferenciar (manter quem não é desse grupo fora dele). Há, no uso desses símbolos, uma clara dinâmica de aceitação de insiders (os que partilham da identidade homossexual) e rejeição de outsiders (os que não partilham dessa identidade). 
A relativa perda do poder de sedução dos produtos e serviços como símbolos é um fato já percebido anteriormente em estudos que focalizaram outras subculturas, como em Schouten \& MacAlexander, sobre donos de Harley-Davidson. Marcas são particularmente importantes no momento de "saída do armário", mas perdem parte do seu fascínio mais tarde.

O uso da estética gay deve ser muito cuidadoso, uma vez que os membros do grupo parecem ser muito influenciados pelo grupo em si, mas não pela mídia. Eles se consideram lançadores de moda: marcas que fazem sucesso na comunidade são posteriormente adotadas por heterossexuais, num forte movimento de comunicação interpessoal. O grupo esteticamente mais próximo da vanguarda nos hábitos inspira a adoção de novidades pelos grupos imediatamente inferiores em inovação. Marcas adotadas por heterossexuais dessa maneira podem acabar sendo abandonadas pelo grupo gay, que sai à procura de outras novidades. Eles valorizam essa condição de inovadores. Assim, talvez seja pouco aconselhável a adoção de estratégias de comunicação de massa para o posicionamento de marcas destinadas aos grupos gays.

Para futuras pesquisas, sugerimos que as mesmas relações que foram alvo de análise neste estudo sejam investigadas junto a grupos de homossexuais com características diferentes das dos nossos entrevistados. Homens mais velhos, casais, pessoas das classes econômicas $C, D$ e $E$, transexuais, lésbicas e "ursos". O público é extremamente diverso, e as características desses diferentes grupos podem ser igualmente muito distintas. 


\section{Referências}

ALDRICH, R. Homosexuality and the city: an historical overview. Urban Studies, v.41, n.9, p.1719-1737, 2004.

BELK, R. W. Possessions and the extended self. Journal of Consumer Research, v.15, p.139-168, Sep. 1988.

BRANCHIK, B J. Out in the market: a history of the gay market segment in the United States. Journal of Macromarketing, v.22, n.1, p.86$97,2002$.

CARMO, M. S. 0 processo do cientista em formação - o quotidiano de uma pós-graduação nível sete (Capes). 2001. Originalmente apresentado como dissertação (Mestrado) - Departamento de Bioquímica Médica, Universidade Federal do Rio de Janeiro, 2001.

CASS, V. C. Homosexual identity: a concept in need of definition. Journal of Homosexuality, v.9, p.105-126, 1984.

CASTR0, D. Canal gay "nacional" sai em março a R\$30. Folha Online, São Paulo, fev. 2005. Disponível em: <http://www1.folha.uol.com.br/folha/ilustrada/ult90u49211.shtml> Acesso em: 23 fev. 2005.

ELIASON, M. J. Identity formation for lesbian, bisexual and gay persons: beyond a "minoritizing" view. Journal of Homosexuality, v.30, n.3, p.31-58, 1996.

FUGATE, D. L. Evaluating the US male homosexual and lesbian population as a viable target market segment. Journal of Consumer Marketing, v.10, n.4, p.46-57, 1993.

GO0DE, E. Deviant behavior. Englewood Cliffs, NJ: Prentice-Hall, 1990.

HALL, S. A identidade cultural na pós-modernidade. Rio de Janeiro: DP\&A, 2004.

HASLOP, C.; HILL, H.; SCHIMIDT, R. A. The gay lifestyle - spaces for a subculture of consumption. Marketing Intelligence \& Planning, v.16, n.5, p.318-326, 1998.

KATES, S. M. Twenty million new customers! Understanding gay men's consumer behavior. New York: Harrington Park Press, 1998.

.The protean quality of subcultural consumption: an ethnographic account of gay consumers. Journal of Consumer Research, v.29, p.383-399, 2002.

The dynamics of brand legitimacy: an interpretative study in the gay men's community. Journal of Consumer Research, v.31, p.455-464, 2004.

LECUMBERRI, B. França terá canal de TV voltado para público homossexual. Folha Online, São Paulo, set. 2004. Disponível em: <http://www1.folha.uol.com.br/folha/ilustrada/ult90u47602.shtml> Acesso em: 23 fev. 2005.

MASCETTI, I.; PEREIRA, B. N. Self, autoconceito e identidade: uma revisão crítica. In: SIMPÓSIO DE GESTÃO EM ESTRATÉGIA EM NEGÓCIOS DA UFRRJ, 2004.

McCRACKEN, G. The long interview. Canada: Sage Publications, 1988.

Cultura e consumo: novas abordagens ao caráter simbólico dos bens e das atividades de consumo. Rio de Janeiro: Mauad, 2003.

MIRANDA, A. P., GARCIA, C.; LEÃO, A. Moda e envolvimento: cada cabide, uma sentença. In. ENCONTRO NACIONAL DOS PROGRAMAS DE PÓS-GRADUAÇÃO EM ADMINISTRAÇÃO, 2001, Campinas. Anais... Campinas, 2001

MORGAN, G. Imagens da organização. Rio de Janeiro: Atlas, 2000.

NUNAN, A. Homossexualidade: do preconceito aos padrões de consumo. Rio de Janeiro: Caravansarai, 2003.

PEÑALOZA, L. We're here, we're queer, and we're going shopping! A critical perspective on the accommodation of gays and lesbians in the U.S. marketplace. Journal of Homosexuality, v.31, n.1/2, p.9-41, 1996. 
SCHOULTEN, J. W. Selves in transition: symbolic consumption in personal rites of passage and identity reconstruction. Journal of Consumer Research, v.17, p.412-425, 1991.

; McALEXANDER J. H. Subcultures of consumption: an ethnographic of the new bikers. Journal of Consumer Research, v.22, p.4361, 1995.

SILOS REPRESENTAÇÕES. Relatório de consultoria preparado para a revista G Magazine, 1999. (Documento interno, não publicado).

SIRGY, M. J. Self-concept in consumer behavior: a critical review. Journal of Consumer Research, v.9, p.287-300, Dec. 1982.

TREVISAN, J. S. Devassos no paraiso: a homossexualidade no Brasil, da colônia à atualidade. 5.ed. Rio de Janeiro: Record, 2000.

TROIDEN, R. R. Self, self-concept, identity and homosexual identity: constructs in need of definition and differentiation. Journal of Homosexuality, v.10, p.97-109, 1984.

The formation of homosexual identities. Journal of Homosexuality, v.17, n.1/2, p.43-73, 1989.

TURNER, V. W. O processo ritual. Petrópolis: Vozes, 1974.

WALTERS, A. S.; MOORE, L. Attention all shoppers, queer customers in aisle two: investigating lesbian and gay discrimination in the market place. Consumption, Market and Culture, v.5, n.4, p.285-303, 2002. 